\title{
EFFECT OF RECLAIMED ASPHALT PAVEMENT STABILIZATION ON THE MICROSTRUCTURE AND STRENGTH OF BLACK COTTON SOIL
}

\author{
Mustapha Mohammed Alhaji ${ }^{*}$, Musa Alhassan ${ }^{1}$ \\ ${ }^{1}$ Civil Engineering Department, School of Engineering and Engineering Technology, Federal \\ University of Technology, P.M.B. 65, Minna, Niger State, Nigeria
}

(Received: June 2017 / Revised: January 2018 / Accepted: June 2018)

\begin{abstract}
Black Cotton Soil (BCS) collected from Guyuk, Adamawa State- North-eastern Nigeria, was treated with 0 to $100 \%$ Reclaimed Asphalt Pavement (RAP) in $10 \%$ steps to evaluate the microstructure and strength of the compacted mixtures. The index property results show that the BCS and RAP are classified under clay of high plasticity $(\mathrm{CH})$ and poorly graded sand (SP) respectively, according to the Unified Soil Classification System (USCS). An extraction test gave a RAP bitumen content of 5.99\%, which is within the value of 5-6\% recommended in the literature. An x-ray diffraction test carried out on both the BCS and RAP showed that the BCS predominantly consisted of quartz, microcline, albite and kaolinite, which is similar to the results obtained in the literature, while the RAP, however, consisted of quartz, albite, orthoclase, phylogopite and actinolite, which is slightly different to what is reported in the literature, probably due to the source of the bitumen. The results of compaction, at a modified energy level, conducted on the mixtures, show that the Maximum Dry Density (MDD) increased from 1.890 to $2.034 \mathrm{mg} / \mathrm{m}^{3}$ at $30 \%$ RAP content, after which the value fell to 1.925 $\mathrm{mg} / \mathrm{m}^{3}$ at $100 \%$ RAP content. The Optimum Moisture Content (OMC) however, decreased from $13.7 \%$ at $0 \%$ RAP, to $8.8 \%$ at between $40-60 \%$ RAP content, after which the value increased marginally to $9.5 \%$ at $90 \%$ RAP. Similar to the MDD, the California Bearing Ratio (CBR) increased from $11 \%$ at $0 \%$ RAP to a maximum of $35 \%$ at $30 \%$ RAP content, after which the value fell to $5 \%$ at $100 \%$ RAP content. $30 \%$ RAP is therefore the optimal mixture giving the highest strength and can be used as a sub-base material for roads with light traffic use, according to the Nigerian General Specification for Road and Bridge Works. Hence the 3.07\% bitumen obtained for this mixture can be adopted as the fixation point for BCS-RAP mixtures. Durability was found to be far lower than the resistance to loss in strength of $80 \%$ suggested in the literature.
\end{abstract}

Keywords: Black cotton soil; Durability; Microstructure; Reclaimed asphalt pavement; Strength

\section{INTRODUCTION}

Black cotton soil (BCS) is a problematic clay soil found in many regions of the world, including Nigeria and India. Its problem stems from its potential for expansion in the presence of moisture, and for shrinkage with subsequent loss of moisture. This behavior usually results in the failure of light structures placed on it. These properties are as a result of montmorillonite and and smectite clay minerals in the soils (Ola, 1974; Osinubi, 1999; Ogundalu \& Oyekan,

\footnotetext{
*Corresponding author's email: a.mustapha@futminna.edu.ng, Tel. +2348036133082

Permalink/DOI: https://doi.org/10.14716/ijtech.v9i4.435
} 
2014; Kaushal \& Gulerie, 2015). According to Gidigasu and Gawu (2013), black cotton soil is found in 254 million hectares of the ice-free part of the world, of which 72 million hectares are in India. The large area covered by this soil in the north-eastern part of Nigeria makes it necessary for long stretches of roads to be constructed over the deposit. This usually results in early failure of the pavement structure because of the expansion and shrinkage of the subgrade black cotton soil. The long distances involved in obtaining better replacement soil material in this region make road construction costs high.

In order to avert the damages caused by BCS, much research has been conducted to modify or stabilize the soils using various chemicals to improve its physical and geotechnical properties. Some researchers (Ola, 1974; Osinubi, 1999; Gaikwad et al., 2014) used lime to either modify or stabilized the soil, resulting in improvement in its physical and to some extent, geotechnical properties. Other researchers (Naik \& Chandrashekhar, 2000; Modak et al., 2012; Hakari \& Puranik, 2012; Ramlakhan et al., 2013; Mudgal et al., 2014; Patel \& Mahiyar, 2014; Rajput \& Yadav, 2015; Mir, 2015) worked on the admixture stabilization of BCS using mixtures of lime, fly ash, rice husk ash, sugarcane bagasse ash, electric arc furnace dust and stone dust. These materials were used individually and mostly in conjunction with lime to improve the physical and geotechnical properties of the soil. All these authors recorded a measurable improvement in the properties of the $\mathrm{BC}$ soils. The mechanism behind the use of these chemical stabilizers is that lime possesses a substantial amount of calcium oxide, which reacts with the pozzolanic ashes that contain a high level of amorphous silica to form cementatious calcium silicate hydrates. These, apart from causing flocculation of the clay particles into silt-sized particles, cement the resultant particles together to form a solid mass. These processes help to modify the soil and even increase the strength of the stabilized black cotton soil.

Reclaimed Asphalt Pavement (RAP) is asphalt removed from failed road surfaces for the purpose of maintenance or reconstruction of the surface (Mustapha et al., 2014). While this material is reused appropriately in most developed countries, in developing countries such as Nigeria, it is thrown away indiscriminately and allowed to degrade the environment. RAP contains aggregates which can improve the stability of deficient soils and bitumen, which gives adhesion to soil particles and hence contributes to the strength of the soil. The use of RAP to stabilize soils has the double benefit of protecting the environment and using waste to generate wealth.

Many studies have been carried out on the possible use of RAP to improve the physical and geotechnical properties of deficient soils. Suebsuk et al. (2014) studied the effect of RAP on the compaction characteristics and unconfined compressive strength (UCS) of cement-treated soil RAP mixtures. They adopted porosity as a state parameter for assessing the strength of the mixed material. Their results showed that as RAP content increases, the OMC tended to decrease to an optimum soil-RAP ratio of 50/50. The asphalt fixation point was recorded to be at an asphalt content of 3.5\% (50/50 soil-RAP ratio). Rupnow et al. (2015) conducted a case study on the stabilization of a RAP-soil mixture with class $\mathrm{C}$ fly ash for use as a sub-grade. They used a Dynamic Cone Penetration (DCP) test to evaluate the strength gain in the field. A UCS test and consolidated undrained triaxial compression tests were carried out in the laboratory. The DCP test results show a time-dependent strength gain due to the cementing and pozolanic action. The falling weight deflectometer results show increased pavement durability and performance. Li et al. (2008) studied the case history of the fly ash stabilization of RAP material. They used an existing hot-mixed asphalt base and sub-grade to depth of $30 \mathrm{~cm}$ to form Reclaimed Pavement Material (RPM). The RPM blended with $10 \%$ fly ash by water was compacted and used as a new pavement. CBR, resilient modulus $\left(\mathrm{M}_{\mathrm{r}}\right)$ and UCS tests were conducted on the SRPM prepared in the field and in the laboratory. The results showed laboratory CBR ranging between 70 and $94 \%, \mathrm{M}_{\mathrm{r}}$ between 78 and $119 \mathrm{MPa}$ and UCS between 
284 and $454 \mathrm{kPa}$. The results of the unstabilized RPM show CBR between 3 and 17\%, and $\mathrm{M}_{\mathrm{r}}$ between 46 and 50MPa. In-situ falling weight deflectometer testing conducted after one year of construction revealed that the pavements had not deteriorated.

Edeh et al. (2012) studied the reclaimed asphalt pavement-lime stabilization of clay as a highway pavement material. They obtained an unsoaked CBR of $36.56 \%$ and a 24 hour soaked CBR of $34.23 \%$, concluding that the material could be used for sub-grade and sub-base courses.

A study of the use of RAP materials in flexible pavements was carried out by Mishra (2015). Compacted density ranging from $1.500 \mathrm{~g} / \mathrm{cm}^{3}$ to $1.950 \mathrm{~g} / \mathrm{cm}^{3}$ was observed, while the asphalt content ranged from 5-6\%. The CBR of 100\% RAP ranged from 20-25\%. Stabilization of lateritic soil using RAP and sugarcane bagasse ash was studied by Joshua (2014), who observed that the MDD increased from $1.771 \mathrm{mg} / \mathrm{m}^{3}$ for natural lateritic soil to $1.79 \mathrm{mg} / \mathrm{m}^{3}$ at $40 \%$ laterite-60\% RAP. Kamel et al. (2016) worked on an evaluation of the suitability of RAP for sub-bases, and from an extraction test observed the bitumen content of RAP to be $5.09 \%$ and maximum CBR to be $61.2 \%$ in a $50 \%$ soil-50\% RAP mixture.

Recycled Concrete Aggregate (RCA) and Mixed Recycled Aggregate (MRA) were studied by Garach et al. (2015) using Scanning Electron Microscopy (SEM) and X-ray Diffraction (XRD) for possible use as road pavement material. The XRD showed a significant proportion of dolomite, chlorite, calcite and quartz in both the RCA and the MRA. The SEM pictures showed brick and calcium silicate. SEM images of RAP and fly ash (FA) as well as the XRD for RAP and FA, were presented by Hoy et al. (2016). The XRD of RAP contained calcite magnesium, dolomite, quartz, hematite and mulite.

The aim of this research, therefore, is to study the microstructure and strength of compacted mixtures of BCS and RAP, with the objective to use RAP, which is a waste product, to stabilize highly soft and expansive BCS.

\section{MATERIALS AND METHODS}

The materials used in the study included black cotton soil (Figure 1), collected $10 \mathrm{~km}$ from Numan town in Adamawa State, Nigeria. It was collected using the disturbed sampling method, and the sample was prepared according to the method highlighted in BS 1377 (1992). Black cotton soil is fine grained and classified as clay of high plasticity $(\mathrm{CH})$ under the unified soil classification system. It requires coarse aggregate to improve its strength and stability. The second material used was Reclaimed Asphalt Pavement (Figure 2), which was collected manually from along the Minna-Bida road in Niger state, Nigeria. The RAP was dried and pulverized to enable it to pass through a $5.0 \mathrm{~mm}$ British Standard sieve before being used in the study. This RAP mainly contained coarse material coated with bitumen.



Figure 1 Black cotton soil

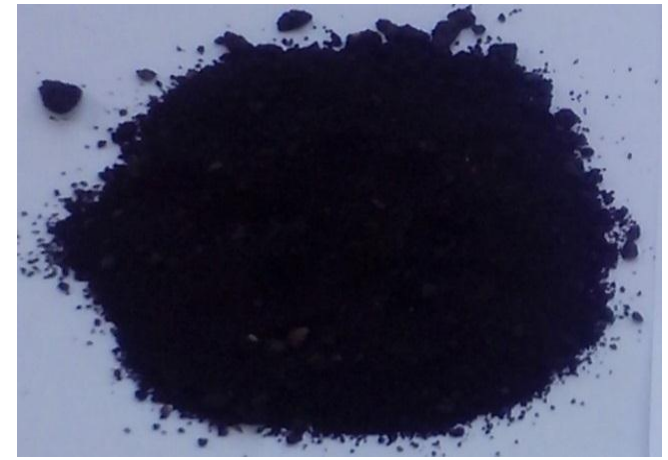

Figure 2 Reclaimed asphalt pavement 
The method used in the study involved heating the RAP openly, on a stove to $100^{\circ} \mathrm{C}$ with a thermocouple used to measure the temperature during the heating. This temperature is far above the melting temperature of asphalt which is $60^{\circ} \mathrm{C}$. The heating allowed some of the bitumen which had remained bound to the aggregates to melt away from it. The hot RAP was then removed from the stove and immediately mixed with BCS so as to allow the melted bitumen to coat some of the clay particles. The mixture was made at ratios of 0:100, 10:90, 20:80, 30:70, $40: 60,50: 50,60: 40,70: 30,80: 20,90: 10$ and 100:0. For small scale construction or maintenance, this mixture can be made manually on site by heating the RAP in large drums to the required temperature after which it is mixed with BCS before placement and subsequent compaction.

An extraction test was then carried out on the mixtures using the method highlighted in BS 2343 (1997). This was to obtain the corresponding bitumen in each of the RAP- BCS mixtures. A physical properties test, including grain size analysis, liquid limit, plastic limit and specific gravity was conducted on the natural soil, while grain size analysis was carried out on the natural BCS and all the RAP-BCS mixtures.

A compaction test, CBR test and durability test were conducted on the BCS treated with 0 to $100 \%$ RAP in $10 \%$ steps. The compaction test was carried out at a modified energy level, in accordance with BS 1377 (1992). For the durability test, the samples were compacted in split molds with perforated ends (Figures 4 and 5).

X-ray diffraction was conducted at the National Geosciences Research laboratory of the Nigeria Geological Survey Agency (NGSA), in Kaduna State, Nigeria (NGRL/OP/5334/2017/0049) on the natural BCS and RAP only. Scanning electron microscopy was also carried out on the compacted specimens of all the mixtures in the Chemical Engineering Department, Ahmadu Bello University, Zaria, Nigeria. This was to evaluate the individual mineralogy of the natural BCS and RAP and also to visualize the microstructures of all the compacted mixtures.



Figure 3 Specimens used for durability test

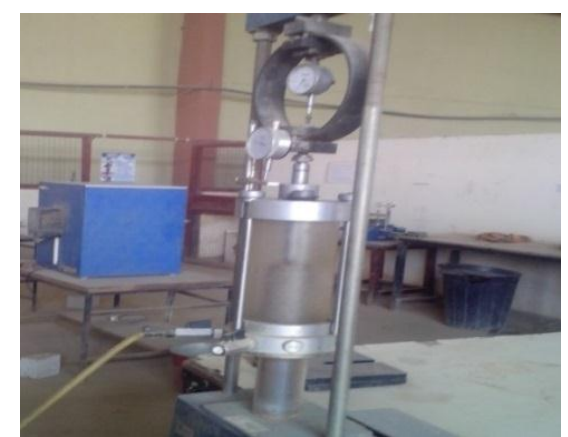

Figure 4 Unconfined compressive strength test

The method used in this study to evaluate durability, and which is more appropriate for tropical regions such as Nigeria, was determination of resistance to loss in strength by immersion of the specimens in water (Ola, 1974). $5 \mathrm{~cm}$ diameter and $10 \mathrm{~cm}$ length split cylindrical molds, whose covers were perforated on both sides, were used for the durability test. Both natural and mixed soil specimens were compacted in the split mold at the modified energy level. For each mixture, two samples were extruded and kept in polythene bags, while two other specimens were both left in the cylindrical mold for 24 hours, after which the specimens in the polythene bags were tested for Unconfined Compressive Strength (Figure 4), while the samples in the split molds were soaked for 72 hours. The soaked samples were then carefully, and with minimal disturbance, removed from the split molds and tested. The ratio between the strength of the un- 
soaked specimens and that of the soaked ones were each evaluated to obtain the resistance to loss in strength of the BCS-RAP mixtures.

CBR tests were also conducted on the specimens compacted at the modified energy level and soaked for 48 hours as specified by the Nigeria General Specification for Roads and Bridge Works (1997) for materials to be used as the sub-base course for road structures.

\section{RESULTS AND DISCUSSION}

\subsection{Index Properties}

The results of the index properties of the natural BCS and RAP are shown in Table 1. The graph of the BCS grain size shows gap-graded quality between sieve sizes $0.008 \mathrm{~mm}$ and 0.05 $\mathrm{mm}$, while the RAP has a coefficient of uniformity of 6 and a coefficient of coverture of 1.63 , which show that it is uniformly graded; hence the two materials lack proper gradation.

The $6.4 \%$ of fines recorded in the RAP is higher than the $0.83 \%$ recorded by Edeh et al. (2012). This is probably due to the manual method of collecting the RAP, which allowed existing fines from the road base to stick to it. The specific gravity of the BCS-RAP mixtures is shown in Figure 8. The graph shows a gradual decrease in specific gravity in line with an increase in RAP content down to $80 \%$, after which the specific gravity drops sharply to $100 \%$ RAP content. This trend is due to the relatively higher value of specific gravity (2.49) recorded for the BCS compared to the relatively lower value (2.01) recorded for the RAP. The specific gravity value recorded for $100 \%$ RAP is within the 1.94-2.30 specified by FHWA (2008) for RAP materials. Replacement of high specific gravity BCS with low specific gravity RAP, resulted in a gradual decrease in specific gravity until all the BCS was replaced with RAP.

Table 1 Index properties of natural black cotton soil and reclaimed asphalt pavement

\begin{tabular}{lcc}
\hline \multirow{2}{*}{ Description } & \multicolumn{2}{c}{ Quantity } \\
\cline { 2 - 3 } & Natural Black Cotton Soil & Reclaimed Asphalt Pavement \\
\hline Gravel (\%) & 0.0 & 7.6 \\
Sand (\%) & 42.8 & 86.0 \\
Silt (\%) & 34.9 & 6.4 \\
Clay (\%) & 22.3 & - \\
Liquid Limit (\%) & 52.4 & - \\
Plasticity Index (\%) & 26.3 & - \\
Specific gravity & 2.49 & 2.01 \\
MDD (Mg/m ${ }^{3}$ ) & 1.890 & 1.925 \\
OMC (\%) & 13.7 & 8.0 \\
Classification (USCS) & CH & SP \\
Classification (AASHTTO) & A-7-6 & A-1-a \\
\hline
\end{tabular}

As seen in Table 1, the natural BCS is classified under A-7-6 according to the American Association of State Highway and Transportation Officials (AASHTO, 1982) soil classification system and as clay of high plasticity $(\mathrm{CH})$ according to the Unified Soil Classification System (USCS), while the RAP is classified under A-1-a according to AASHTTO, and SP according to USCS. These classifications show that the BCS cannot be used for any component of a road structure and will therefore require stabilization to improve its strength and durability properties. 


\subsection{Extraction Test}

The results of the extraction test show a gradual increase in bitumen content, from $0 \%$ at $0 \%-100 \%$ to $5.99 \%$ at $100 \%-0 \%$. The $5.99 \%$ bitumen content of $100 \%$ RAP is within the 5$6 \%$ range reported by Mishra (2015) for most RAP materials.

\subsection{X-Ray Diffraction Test}

The results of the X-ray diffraction test show that the BCS consists predominantly of quartz, microcline, albite and kaolinite. This is similar to the XRD results obtained for BCS in Nigeria by Ogundalu \& Oyekan (2014). The RAP, however, consists of quartz, albite, othorclase, phlogopite and actinolite. This is slightly different from the RAP XRD results obtained by Hoy et al. (2016), which included calcium-magnesium, dolomite, quartz, calcite, mullite, hematite and calcium sulphate. Some of these elements are contained in the complex actinolite, which contains $\mathrm{Fe}, \mathrm{Mn} \mathrm{Mg}, \mathrm{Ca}, \mathrm{Na}, \mathrm{Si}, \mathrm{Al}, \mathrm{K}, \mathrm{H}, \mathrm{O}, \mathrm{F}$ and $\mathrm{Cl}$. This variation can also be attributed to the source of the bitumen used.

\subsection{Compaction Characteristics}

The results of the compaction characteristics of the BCS-RAP mixtures are shown in Figure 5. The trend shows an increase in MDD with an increase in RAP content from $1.890 \mathrm{mg} / \mathrm{m}^{3}$ at $0 \%$ RAP content to $2.036 \mathrm{mg} / \mathrm{m}^{3}$ at $30 \%$ RAP content, after which the MDD decreases to 1.925 $\mathrm{mg} / \mathrm{m}^{3}$ at $100 \%$ RAP. This trend is common for all mechanical stabilization of clay soils. The three components that exist in the mixture (clay, bitumen and aggregates) contribute individually to the density of the compacted mixture. The addition of RAP to the clay contributes both high specific gravity aggregate and very low specific gravity bitumen to the mixture. While the aggregate tends to increase the MDD, the bitumen tends to decrease it. At a RAP content of up to $30 \%$, the effect of the high specific gravity aggregate dominates, and therefore the MDD increases to its maximum value of $2.036 \mathrm{mg} / \mathrm{m}^{3}$ at $30 \%$ RAP content. Beyond this level, the very low specific gravity bitumen becomes substantial such that the average of its combined effect tends to reduce the density (MDD) of the mixture. The bitumen content of the mixture (3.07) is called the fixation point for RAP-BCS mixtures (Menglin et al., 2016). This value is lower than the 3.5\% recorded by Menglin et al. (2016) for 50\% RAP-50\% soil. A further increase in RAP content, results in more bitumen, whose average specific gravity with the aggregate decreases, consequently decreasing the MDD.

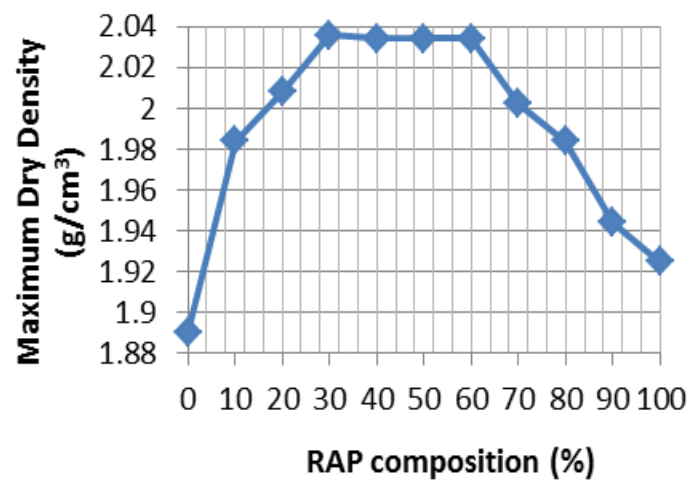

Figure 5 Variation in MDD with RAP content

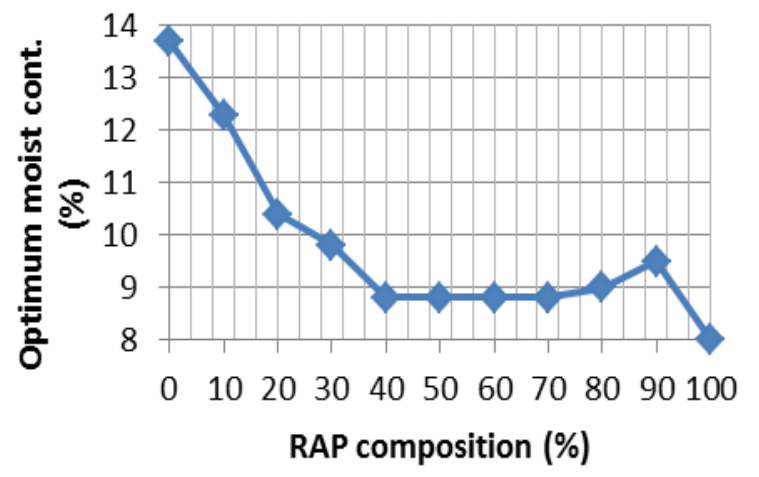

Figure 6 Variation in OMC with RAP content

The OMC (Figure 6) falls from $13.7 \%$ at $0 \%$ RAP content to $8.8 \%$ at $40 \%$ RAP content. It remains relatively constant at $8.8 \%$ at $70 \%$ RAP content, after which it increases slightly to $9.5 \%$ at $90 \%$ RAP content. The value falls to $8.0 \%$ at $100 \%$ RAP content. The initial decrease results from the increased coating of the BCS by the bitumen. Beyond 40\% RAP content, all the $\mathrm{BCS}$ becomes coated with bitumen, thereby meaning the OMC remains constant. Beyond $70 \%$ 
RAP content, the slight increase in OMC observed is probably due to the poor graded quality of the mixture that must have created extra pore spaces which are occupied by water.

\subsection{Scanning Electron Microscopy (SEM) of the Compacted Mixtures}

The SEM images of the compacted mixtures are shown in Figure 7. Those of $100 \%$ BCS and $100 \%$ RAP are similar to the SEM images of clay presented by Patricio et al. (2016) and Mohanty et al. (2016), and the SEM images of RAP presented by Hoy et al. (2016), PaigeGreen (2010) and Dulaimi et al. (2016). The microstructure of the compacted specimen of $100 \%$ BCS shows fine crystals of particles with visible cracks as observed by Paige-Green (2010). These cracks are more pronounced in the 10\% RAP-90\% BCS. The SEM images of $20 \%$ RAP- $80 \%$ BCS and 30\% RAP-70\% BCS do not show these cracks, but instead an interlocking of particles of varying sizes in a very dense state. The cracks reappear in $40 \%$ RAP-60\% BCS down to $70 \%$ RAP-30\% BCS. Beyond 70\% RAP, the interlocking arrangement of the particles reoccurs, but with a substantial amount of bitumen. This is responsible for the maximum MDD that is observed at $30 \% \mathrm{RAP}-70 \% \mathrm{BCS}$.

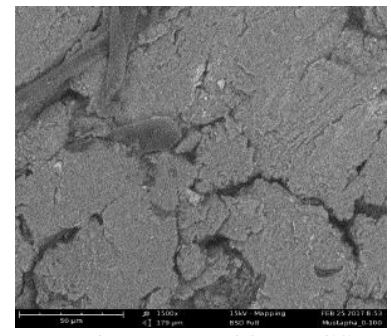

(a) $0 \%$ RAP- $100 \%$ BCS

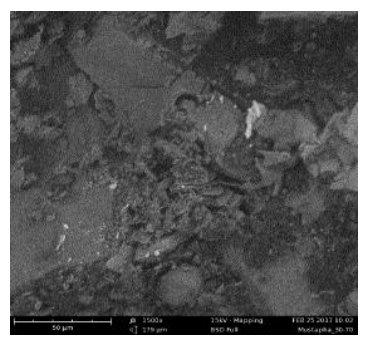

(b) $30 \%$ RAP-70\% BCS

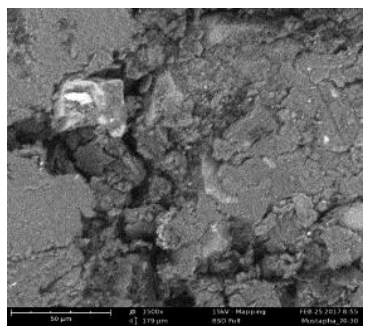

(c) $70 \%$ RAP-30\% BCS



(d) $100 \%$ RAP-0\% BCS

Figure 7 SEM images of selected compacted mixtures of RAP and BCS

\subsection{CBR of the Compacted Mixtures}

The trend of the CBR results is shown in Figure 8. The CBR of the compacted specimens increased from $11 \%$ at $100 \%$ BCS to $35 \%$ at a mixture of $30 \%$ RAP- $70 \%$ BCS, after which the value fell to $5 \%$ at $100 \%$ RAP. The initial increase was due to the introduction of aggregates in to the clay, which improved the grading of the mixture. The grading continued to improve up to a mixture of $30 \%$ RAP-70\% BCS, in which appropriate aggregate was available to be filled by the fine BCS. The amount of adhesion mobilized by the plastic BCS in the mixture at this proportion was optimal, hence the maximum CBR was recorded. The SEM results also show minimal cracking and maximum interlocking of particles at mixture of $30 \%$ RAP-70\% BCS, which is probably responsible for the optimal CBR recorded for that mixture. As seen in Figure 8 , the CBR value of the stabilized BCS was found to be related to the percentage of RAP, with the relationship:

$$
C B R=14.622+0.7903(R A P)-0.0093(R A P)^{2}
$$

The coefficient of determination $\mathrm{R}^{2}$ recorded was 0.904 , which is very close to 1.0 . The maximum soaked CBR of $35 \%$ is above the $30 \%$ minimum recommended by the Nigeria General Specification for Roads and Bridge Works (1997) for soil materials used as sub-bases for roads with light traffic. It can therefore be said that $30 \%$ is the optimal percentage RAP recommended for stabilization of BCS. The mixture should be compacted at a modified compaction energy level. 


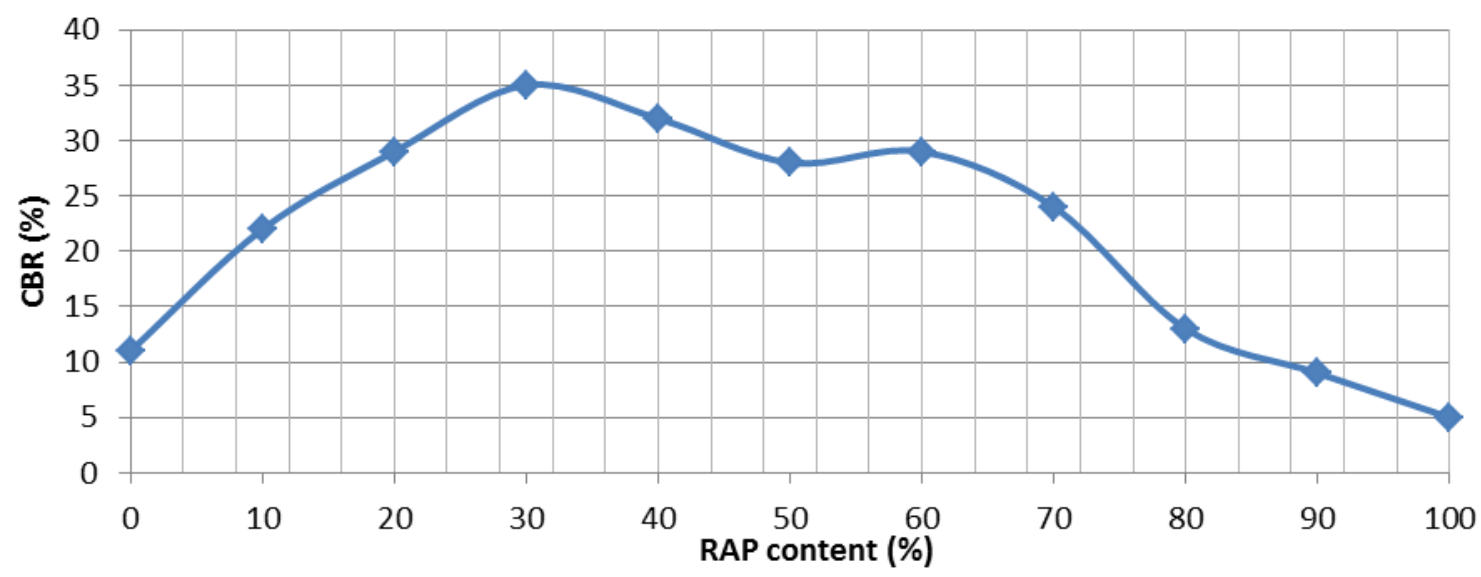

Figure 8 Variation in CBR with increase in percentage RAP

\subsection{Durability Characteristics}

The results of the durability test are shown in Table 2. The resistance to loss in strength is observed to increase from $21.7 \%$ at $0 \%$ RAP to $42.3 \%$ at $40 \%$ RAP, after which the value drops to $8.5 \%$ at $100 \%$ RAP. These values are far below the resistance to loss in strength of $80 \%$ suggested by Ola (1974).

Table 2 Results of the durability test using the loss in strength method due to soaking

\begin{tabular}{lccccccccccc}
\hline \multicolumn{1}{c}{ RAP $(\%)$} & 0 & 10 & 20 & 30 & 40 & 50 & 60 & 70 & 80 & 90 & 100 \\
\hline $\begin{array}{l}\text { Unsoaked } \\
\text { UCS }\left(\mathrm{kN} / \mathrm{m}^{2}\right)\end{array}$ & 388 & 442 & 484 & 592 & 492 & 404 & 346 & 250 & 168 & 102 & 47 \\
$\begin{array}{l}\text { Soaked } \\
\text { UCS }\left(\mathrm{kN} / \mathrm{m}^{2}\right)\end{array}$ & 84 & 120 & 162 & 204 & 208 & 62 & 51 & 34 & 18 & 10 & 4 \\
$\begin{array}{l}\text { Resistance to loss in } \\
\text { strength (\%) }\end{array}$ & 21.7 & 27.1 & 33.5 & 34.5 & 42.3 & 15.3 & 14.7 & 13.6 & 10.7 & 9.8 & 8.5 \\
\hline
\end{tabular}

\section{CONCLUSION}

(1) The BCS studied is classified as A-7-6 and CH based on the AASHTTO and Unified Soil Classification systems respectively, while the RAP studied is classified as A-1-a and SP based on the same systems; (2) A maximum MDD of $2.036 \mathrm{mg} / \mathrm{m}^{3}$ was recorded at a mixture of $30 \%$ RAP-70\% BCS. The microstructural images of the compacted specimens from SEM reveal the best particle interlocking arrangement in this mixture; (3) A maximum CBR of $35 \%$ was recorded at $30 \%$ RAP $-70 \%$ BCS. This value is above the $30 \%$ minimum recommended by the Nigeria General Specification for Roads and Bridge Works (1997) for soil material to be used in road sub-base; (4) The durability of the RAP-BCS mixtures was observed to attain a maximum value at $40 \%$ RAP-60\% BCS. However, all the values recorded are below the $80 \%$, suggested by Ola (1974); (5) Black cotton soil stabilized with RAP can be used as sub-base material for roads with light traffic based on the specifications of the Nigeria General Specification for Roads and Bridge Works (1997). However, care must be taken to prevent ingress of water into the sub-base, so as to avoid rapid loss of strength due to the lack of durability. 


\section{REFERENCES}

American Association of State Highway and Transportation Officials, 1982. AASHTO Materials: Standard Specification for Transportation Materials and Methods of Sampling and Testing, Part I: Specifications. The Association, Washington, D.C., USA

BS 1377, 1992. Methods of Testing Soil for Civil Engineering Purposes. British Standards Institute, London, England

Dulaimi, A., Al-Nageim, H., Hashim, K., Ruddock, F., Seton, L., 2016. Investigation into the Stiffness Improvement, Microstructure and Environmental Impact of a Novel Fast-curing Cold Bituminous Emulsion Mixture. In: $6^{\text {th }}$ Eurasphalt and Eurobitume Congress, Prague, 1-3 June, Czech Republic, pp. 1-12

Edeh, J.E., Eberemu, A.O., Abah, A.B., 2012. Reclaimed Asphalt Pavements-lime Stabilization of Clay as Highway Pavement Materials. Journal of Sustainable Development and Environmental Protection, Volume 2(3), pp. 62-75

Gaikwad, K.S., Mehta, K.S., Sonecha, R.J., Daxini, P.D., Ratanpara, P.B., 2014. Analysis of Engineering Properties of Black Cotton Soil and Stabilization using by Lime. International Journal of Engineering Research and Application, Volume 4(5), pp. 25-32

Garach, L., Lopez, M., Agrela, F., Ordonez, J., Alegre, J., Moya, J.A., 2015. Improvement of Bearing Capacity in Recycled Aggregates Suitable for Use as Unbound Road Sub-base. Materials, Volume 8(12), pp. 8804-8816

Gidigasu, S.S.R., Gawu, S.K.Y., 2013. The Mode of Formation, Nature and Geotechnical Characteristics of Black Cotton Soil: A Review. Standard Research Journals, Volume 1(14), pp. 377-390

Hakari, U.D., Puranik, S.C., 2012. Stabilisation of Black Cotton Soil using Fly Ash, HubballiDharwad Municipal Cooperation Area, Karnataka, India. Global Journal of Researches in Engineering, Volume 12(2), pp. 21-29

Hoy, M., Horpibulsuk, S., Arulrajah, A., 2016. Strength Development of Recycled Asphalt Pavement-fly Ash Geopolymer as a Road Construction Material. Construction and Building Materials, Volume 117, pp. 209-219

Kamel, M.A., Al-Bustami, N.M., Al-Sulami, B.T., 2016. Evaluation of the Suitability of Recycled Asphalt Pavement (RAP) for Subbases. International Journal of Emerging Technology and Advanced Engineering, Volume 6(5), pp. 212-215

Kaushal, V., Guleria, S.P., 2015. Geotechnical Investigation of Black Cotton Soils. International Journal of Advances in Engineering Sciences, Volume 5(2), pp. 15-22

Li, L., Benson, C.H., Edil, T.B., Hatipoglu, B., 2008. Sustainable Construction Case History: Fly Ash Stabilization of Recycled Asphalt Pavement Material. Geotechnical and Geological Engineering, Volume 26, pp. 177-187

Menglin, H., Suksun, H. and Arul, A., 2016. Strength Development of Recycled Asphalt Pavement-Fly Ash Geopolymer as a Road Construction Material. Construction and Building Materials, Volume 117, pp. 209-219

Mir, B.A., 2015. Some Studies on the Effect of Fly Ash and Lime on Physical and Mechanical Properties of Expansive Clay. International Journal of Civil Engineering, Volume 13(3 \& 4b), pp. 203-212

Mishra, B., 2015. A Study on Use of Reclaimed Asphalt Pavement (RAP) Materials in Flexible Pavements. International Journal of Innovative Research in Science, Engineering and Technology, Volume 4(12), pp. 12170-12177

Modak, P.R., Nangare, P.B., Nagrale, S.D., Nalawade, R.D, Chavhan, V.S., 2012. Stabilization of Black Cotton Soil using Admixtures. International Journal of Engineering and Innovative Technology, Volume 1(5), pp. 1-3 
Mohanty, S.K., Pradhan, P.K., Mohanty, C.R., 2016. Stabilization of Expansive Soil using Fly Ash and Lime. In: International Conference on Advanced Materials Technologies (ICAMT) 2016, Dadi Institute of Engineering and Technology, India

Mudgal, A., Sarkar, R., Sahu, A.K., 2014. Effect of Lime and Stone Dust in the Geotechnical Properties of Black Cotton Soil. International Journal of GEOMATE, Volume 7(2), pp. $1033-1039$

Mustapha, A.M., Jibrin, R., Etsuworo, N.M., Alhassan, M., 2014. Stabilization of A-6 Lateritic Soil using Cold Reclaimed Asphalt Pavement. International Journal of Engineering and Technology, Volume 4(1), pp. 52-57

Naik, C., Chandrashekhar, A.S., 2000. Geotechnical Characteristics of Black Cotton Soil Mixed with Fly Ash: An Experimental Evaluation. IOSR Journal of Mechanical and Civil Engineering, pp. 50-54

Nigeria General Specification for Roads and Bridge Works, 1997. Roads and Bridges. Federal Ministry of Works, Abuja, Nigeria

Ogundalu, A.O., Oyekan, G.L., 2014. Mineralogical and Geotechnical Characterization of Maiduguri Black Cotton Soil by X-Ray Diffraction (XRD), X-Ray Photoelectron (XPS) and Scanning Electron Microscopy (SEM). International Journal of Engineering and Technology, Volume 4(6), pp. 345-353

Ola, S.A., 1974. Need for Estimated Cement Requirements for Stabilizing Lateritic Soils. Journal of Transportation Engineering Division, ASCE, Volume 100(2), pp. 379-388

Osinubi, K.J., 1999. Evaluation of Admixture Stabilization of Nigerian Black Cotton Soil. Nigerian Society of Engineers (NSE) Technical Transactions, Volume 34(3), pp. 88-96

Paige-Green, P., 2010. A Preliminary Evaluation of the Reuse of Cementitious Materials. In: Proceedings of the $29^{\text {th }}$ South Africa Transport Conference, Pretoria, 16-19 August, South African, pp. 520-529

Patel, P., Mahiyar, H.K., 2014. An Experimental Study of Black Cotton Soil, Stabilized with Rice Husk Ash, Fly Ash and Lime. International Journal of Engineering Research and Technology, Volume 3(11), pp. 660-665

Patricio, J., Rodrigues, J.K., Lucena, L.C., 2016. Study of Chemical-Mineralogical Properties of Modified Soils with Polymers Addition. E3S Web of Conferences, Volume 9, pp. 1-4

Ramlakhan, B., Kumar, S.A., Arora, T.R., 2013. Effect of Lime and Fly Ash on Engineering Properties of Black Cotton Soil. International Journal of Emerging Technology and Advanced Engineering, Volume 3(11), pp. 535-541

Rajput, S.S., Yadav, R.K., 2015. Effect of Fly-ash on Geotechnical Characteristics of Black Cotton Soil. International Journal for Innovative Research in Science and Technology, Volume 2(3), pp. 9-13

Rupnow, T.D., Franklin, B., White, D.J., 2015. Class C Fly Ash Stabilization of Recycled Asphalt Pavement and Soil: A Case Study, 2015. In: World of Coal Ash (WOCA) Conference, Nasvhille, 5-7 May, TN, pp. 1-19

Suebsuk, J., Suksan, A., Horpibulsuk, S., 2014. Strength Assessment of Cement Treated SoilReclaimed Asphalt Pavement (RAP) Mixture. International Journal of GEOMATE, Volume 6(2) pp. 878-884 